\title{
ANGÚSTIA DE UMA PERDA - CASO \\ MARIA: UMA ABORDAGEM TERAPÊUTICA ${ }^{\mathrm{I}}$
}

\author{
Mónica Costa* \\ Catarina Pinheiro Mota** \\ Cláudia Milheiro***
}

\section{Resumo}

O presente estudo de caso procura discutir a vivência de Maria, de 32 anos de idade, onde está patente uma dinâmica emocional e relacional marcada por sentimentos de angústia. A avaliação revelou uma vivência afetiva de tipo neurótico, apresentando sinais clínicos evidentes da angústia da perda do objeto e da separação afetiva, revelando fortes sentimentos de culpabilidade frente a conflitos internos. É proposta uma intervençâo psicológica no sentido de facilitar a vivência do luto passando pela aceitação e elaboração da perda. O processo de acompanhamento psicológico, concebido no modelo psicodinâmico, surtiu um efeito estruturante, verificando-se uma diminuição da ansiedade como atenuação dos pensamentos ruminativos em torno da morte do pai e dependência da máe. Embora ainda em processo, observou-se uma maior capacidade para pensar sobre os seus sentimentos e emoçóes, facilitando o processo de elaboração dos seus conflitos internos.

Palavras-chave: depressão neurótica; angústia; perda; luto.

* Universidade de Trás-os-Montes e Alto Douro (UTAD), Vila Real, Trás-os-Montes e Alto Douro, Portugal.

** Universidade de Trás-os-Montes e Alto Douro (UTAD), Vila Real, Trás-os-Montes e Alto Douro, Portugal; Centro de Psicologia da Universidade do Porto, Porto, Distrito do Porto, Portugal.

*** Hospital de Magalhães Lemos, Distrito do Porto, Porto, Portugal. 


\begin{abstract}
ANGUISH OF ONE LOST - MARY'S CASE: THERAPEUTIC APPROACH

The present case study intend to discuss the experience of Maria, a 32 years old woman with an emotional and relational dynamics characterize by anguish feelings. The evaluation showed a neurotic type of emotional experience, with obvious clinical signs of anguish from the object's loss and the emotional separation, revealing strong feelings of guilt face to internal conflicts. Psychological intervention is proposed to facilitate the experience of grief through the acceptance of loss elaboration. The process of counseling, designed in the psychodynamic model, has had a structural effect, verifying a decrease in anxiety as well as attenuation of ruminating thoughts about her father's death and mother's dependence. Although still in the process, it was observed a greater capacity to think about their feelings and emotions, facilitating the breeze process of their internal conflicts.
\end{abstract}

Keywords: neurotic depression; anguish; loss; mourning.

\title{
Resumen
}

ANGUSTIA DE UNA PERDIDA - CASO MARÍA: UN ABORDAJE TERAPÉUTICO

Este estudio de caso analiza la experiencia de María, 32 años, con una dinámica emocional y relacional sellada por evidentes sentimientos de angustia. La evaluación reveló un estilo afectivo de tipo neurótico, con signos clínicos evidentes de angustia hacia la pérdida del objeto y la separación emocional, revelando un fuerte sentimiento de culpabilidad de acuerdo con los conflictos internos. Se propone una intervención psicológica en el sentido de facilitar la experiencia de luto a través del desarrollo personal y la aceptación de la pérdida. El proceso de seguimiento psicológico, de acuerdo con el modelo psicodinámico, ha tenido un efecto estructurante, verificando una disminución de la ansiedad como la atenuación de pensamientos ruminativos sobre la muerte de su padre y la dependencia hacia la madre. Aunque todavía permanezca en el proceso, hubo una mayor capacidad de pensar acerca de sus sentimientos y emociones, lo que facilita el proceso de elaboración de sus conflictos internos.

Palabras clave: depresión neurótica; angustia; pérdida; luto.

\section{Introdução}

O presente trabalho debruça-se sobre um caso clínico seguido em contexto hospitalar, destacado enquanto proposta de estudo de caso pela sua relevância 
clínica e implicaçóes terapêuticas. Neste sentido, a temática que versa este trabalho relaciona-se com o desenvolvimento de uma depressão neurótica e as suas contingências na resolução do luto, sendo descrita ao longo da vivência de uma mulher de 32 anos de idade.

$\mathrm{O}$ interesse sobre a psicopatologia em geral e a depressão patológica em específico tem sido crescente, não só por fazer parte do quotidiano de muitos profissionais de saúde mental, mas por constituir um fenómeno marcante no mundo contemporâneo ocidental.

$\mathrm{Na}$ fenomenologia da depressão neurótica encontra-se com frequência a "ideia prevalecente", ou seja, a ideia sobrevalorizada que persiste e permanece e contra a qual o individuo não luta para expulsar da consciência. Esta ideia prevalecente refere-se sempre, segundo Matos (2001), ao medo de ser abandonado pelo objeto, de perder o seu amor. Neste sentido, a depressão neurótica caracteriza-se por um estado mais ou menos permanente, pautado por exacerbaçóes em que o desespero é o sintoma dominante. De uma forma geral, a depressão neurótica é uma disposição depressiva, cuja vida é predominada por um afeto depressivo base (Matos, 2001).

Cabe ressaltar que um luto não resolvido pode agravar uma depressão, assim como uma depressão pode complicar a resolução do luto. Neste sentido, Elizabeth Kübler-Ross (1969) destaca o desenvolvimento de um importante campo de estudos, cujo objeto central é a morte e o sentimento de perda por ela provocado. Desta feita, Kübler-Ross propôs um modelo constituído por cinco estágios, conhecidos como Os Cinco Estágios do Luto, pelos quais as pessoas passam ao lidar com a perda e o luto. Neste sentido, a negação e o isolamento caracterizam o primeiro estágio, entendidos como comportamentos protetores, embora temporários, para lidar com a situação estressante. De uma forma geral, são mantidos até que o individuo consiga assimilar a verdade e/ou aproximar-se de certo equilíbrio psicológico pós-traumático. $\mathrm{O}$ segundo estágio é caracterizado pela raiva e revolta que a pessoa tem da situação, marcada pelo questionamento: por que eu? Neste sentido, nascem a raiva e a revolta dirigidas contra Deus, entre outros. Seguidas pelo terceiro estágio que se designa de negociação, em que a pessoa tenta negociar com ela própria, com os outros ou mesmo com Deus. É uma fase em que a pessoa ainda luta contra a situação vigente, procurando diversos meios de "fugir" da situação. Após a pressão psicológica das fases anteriores, o desgaste físico e emocional traz o quarto estágio, marcado pela depressão. Por fim, na fase de aceitação a pessoa começa a aceitar a situação vigente e pensar em meios racionais de enfrentar os problemas. É a fase em que a pessoa centraliza forças para passar por aquela situação da melhor forma possível (Kübler-Ross, 1969). 
Cabe ressaltar que Kübler-Ross (1969) postulou estes mecanismos de luta para enfrentar situaçóes extremamente difíceis, sem tempo determinado para cada estágio e sem uma ordem concreta. Para além disso, nem todos os indivíduos passam pelos cinco estágios e pode acontecer a estagnação num deles.

Destacamos neste trabalho dificuldades significativas na resolução destas fases, ao que se acresce uma angústia continuada na vivência da paciente. Neste sentido, a vivência da Maria é centrada num exacerbado investimento do objeto primário, sendo que as suas preocupaçóes são centradas, precisamente, no medo desta mudança existencial, isto é, medo em investir e transferir a libido para novos objetos e objetivos. Desta forma, é nesta mudança de rumo que se situa a problemática neurótica, nomeadamente, na angústia condensada no medo do futuro e depressão representada pelo sentimento de abandono e solidão (Matos, 2001).

\section{Metodologia}

\section{Participante - História clínica}

A Maria tem 32 anos, vive em união de fato e reside no Porto, Portugal. A sua aparência geral é concordante com a idade, e tem uma apresentaçáo limpa e cuidada. Mantém numa primeira fase alguma inquietação acompanhada de agitação motora e tremores nas mãos, contudo consegue manter o contato ocular. De uma maneira geral a sua fácies manteve-se congruente com o conteúdo do seu discurso evidenciando uma marcada expressão emocional. Maria foi descrevendo a sua história de forma coerente e organizada. Apresentava-se bem orientada e colaborante com discurso lógico. Apresentava humor depressivo sem ideação suicida e a crítica mantinha-se preservada.

A Maria tem um filho de 10 anos e uma filha de 15 meses. Completou o $9^{\circ}$ ano de escolaridade. É empregada de balcão numa loja de brinquedos, porém neste momento encontra-se em casa por ordem médica desde Outubro de 2010.

Desde os 17 anos que é seguida em psiquiatria no Hospital de São João (H.S.J.), no Porto (Portugal), por patologia depressiva, apontando algumas oscilaçôes de humor pouco significativas (sic). Refere que em momentos de ansiedade registam-se tremores acompanhados de perda total da visão, pelo que manifesta um medo constante em ficar cega (sic). Foi efetuado o despiste de problemas orgânicos, todavia a TAC (Tomografia Axial Computorizada.) e a RMN (Ressonância Magnética Nuclear.) cerebral apresentaram valores normais, tendo 
esses episódios sido atribuídos à ansiedade. Não refere nenhum internamento psiquiátrico. Abandonou o acompanhamento no H.S.J., mas terá continuado com a medicação, mesmo durante a gravidez. Associa o primeiro contato com a psiquiatria à morte de um amigo do irmão, refere que ficou com "medo de tudo e só se sentia bem ao lado da máe" (sic). O acompanhamento em psiquiatria no H.S.J. terminou em 2009. Recentemente, ter-se-á dirigido à médica de família que a encaminhou para o serviço de psiquiatria do Hospital de Magalhães Lemos (H.M.L.), sendo seguida também na consulta de psicologia e nutrição.

Nega antecedentes médicos de relevo. Afirma que nenhuma das suas gravidezes foi planejada, mas, posteriormente, muito desejadas. Refere não ter sofrido complicaçóes durante a gravidez e o parto decorreu sem complicaçóes. Neste momento não está a amamentar. Teve o primeiro filho aos 22 anos, seguido de um agravamento significativo da sintomatologia, não associando a nenhum evento específico. Relativamente à ultima gravidez não se registraram alteraçóes assinaláveis, contudo, desde que o bebé nasceu e regressou à casa, aponta um agravamento da sintomatologia depressiva. Menciona que este agravamento se deveu ao falecimento do pai de uma amiga, com quem mantinha uma relação próxima (sic). Este indivíduo ter-lhe-á dito que "uma vez que a sua bebé nasceu já poderia ficar sem a sua presença" (sic). Desde então Maria refere sentir-se mais triste e angustiada, "sem paciência”, adinâmica, não tolera o ruído nem o chorar da bebé e, por vezes, registra-se insônia terminal. Manifesta pensamentos ruminativos em torno do medo que tem em perder a visão que se traduzem em crises de ansiedade. Refere ter medo de ficar sozinha em casa e náo ser capaz de cuidar dos filhos. Em momentos de ansiedade e "crise" telefona à mãe, que imediatamente vai para junto de Maria, ajudando-a com os cuidados com a bebé, "com a minha mãe sinto-me protegida" (sic). Quando a filha nasceu passou os dois meses seguintes a acompanhar a mãe para o trabalho (sic). Atualmente, vive em casa da mãe com o companheiro e os dois filhos, para que esta a ajude a tomar conta da bebé, mudou-se desde o fim da gravidez (sic). O marido trabalha como instalador de rede de gás. Nega antecedentes familiares psiquiátricos.

O pai faleceu há seis anos por ataque cardíaco, sem antecedentes conhecidos previamente.

História desenvolvimental e familiar

A Maria nasceu no seio de uma gravidez planejada. Nasceu de cesariana e o parto decorreu dentro da normalidade (sic). Todavia a mãe de Maria foi vítima de dois atropelamentos durante a gravidez, embora nenhum deles tenha sido signifi- 
cativo, não necessitando de cuidados médicos de relevo. A mãe afirma que Maria teve um desenvolvimento considerado normal (sic). Desde que nasceu até aos 3 anos permaneceu com a mãe, acompanhando-a para o trabalho. Aos 3 anos de idade ingressa no infantário revelando uma boa adaptação ao novo contexto. De acordo com a mãe, Maria denotou desde sempre facilidade em estabelecer relaçóes de qualidade com os pares, o que facilitou o processo de adaptação (sic). Da mesma forma teve uma boa adaptação aos 7 anos quando da entrada para a escola primária, frequentando no fim das aulas uma instituição de ATL (Actividades de Tempos Livres). Durante os quatro anos do ensino primário Maria manteve um percurso sem qualquer alteração a ressaltar, mantendo um bom rendimento escolar. Aos 8 anos de idade Maria manifesta um medo persistente face à perda dos pais, facto que ocasiona uma maior atenção por parte da mãe que passa a deitar-se com Maria até esta conseguir dormir.

$\mathrm{Na}$ passagem para o $5^{\circ}$ ano, com 11 anos de idade Maria ingressa uma nova instituição escolar perto de casa. Ficou retida no $5^{\circ}$ ano, referindo que a adaptação a esta escola foi "difícil [...] estranhou o facto de ter muitas professoras e haver muita diferença de idade para com os alunos mais velhos" (sic). No $10^{\circ}$ ano Maria sofre uma nova transição no que concerne à instituição escolar, descrevendo um episódio que descreve como "traumático" (sic). Este episódio diz respeito ao falecimento do amigo do irmão, a partir daí começam as queixas, nomeadamente o medo de ir para escola sozinha. Teria 16 anos nesta altura. Refere ter tido uma relação próxima com este rapaz, até porque era amigo do irmáo e frequentava a sua casa. De referir que este rapaz morreu atropelado, fato que parece ter afetado Maria, embora náo estivesse presente no momento do acidente. Maria recorda o funeral e ter "memorizado na cabeça a imagem deste rapaz no caixão, afirmando que ficou mais impressionada ainda por ter falecido tão novo e pensar que podia ter sido o irmão, que estava presente no momento do acidente" (sic). Desde esta data Maria reporta sonhos que se relacionam com a sensação de asfixia: "aperto no pescoço". Após este acidente, e de acordo com a mãe, Maria manifesta alterações comportamentais, nomeadamente isolamento, mantendo contato apenas com as pessoas do seu núcleo familiar. Nesta altura deixa de ir à escola começando a acompanhar a mãe para o trabalho. Reporta uma ansiedade significativa quando confrontada com qualquer situação de emergência - "bastava ouvir uma ambulância que ficava ansiosa e a sentir medo que alguma coisa acontecesse" (sic). Depois deste episódio inicia a sintomatologia de medo constante, angústia e falta de ar (sic), altura em que começou a ser seguida no H.S.J.. Refere melhoria significativa de sintomatologia pelo que terá optado por deixar a medicação e as consultas de forma voluntária. Aquando do nascimento 
do filho aponta um episódio de "falta de visão e a partir daí ter começado tudo novamente" (sic). Maria tem um irmão três anos mais novo com quem mantém desde sempre um bom relacionamento.

\section{Objetivos}

\section{Motivo do encaminhamento e pedido de acompanhamento}

Maria foi encaminhada para o Hospital de Magalhães Lemos pelo médico de família do Centro de Saúde da sua área de residência. Desde então tem acompanhamento na consulta de psiquiatria do Hospital de Magalhães Lemos, que por sua vez a encaminhou para a consulta de psicologia por quadro compatível com episódios depressivos recorrentes, com componente ansioso marcado. Maria ressalta a postura dependente acompanhada de oscilaçóes de humor pouco significativas, e em momentos de ansiedade e tremores acompanhados de perda total da visão. O pedido foi realizado pela própria, primeiramente ao médico de família e posteriormente na consulta de psiquiatria e psicologia, destacando mal-estar geral e incapacidade significativa no desenvolvimento das suas atividades diárias (sic).

\section{Procedimento}

Trata-se de um trabalho desenvolvido no âmbito da consulta psicológica do Serviço de Psicologia do Hospital de Magalhães Lemos, sendo selecionado enquanto proposta de estudo de caso pela sua relevância clínica em torno da depressão neurótica e pertinência do processo psicoterapêutico seguido na intervenção. Todos os dados pessoais do paciente foram salvaguardados, assim como todas as questôes éticas inerentes ao processo, obtendo-se aprovação da Direção Clínica do Hospital de Magalhães Lemos para o desenvolvimento e divulgaçáo deste trabalho. A exploração do caso e a elaboração do diagnóstico foram realizadas tendo em conta a análise da história clínica da paciente e o recurso a meios auxiliares de diagnóstico, nomeadamente o teste de personalidade de Rorschach (sistema compreensivo de Nina Raus, Rorschach, 1953), o SCL-90 (Symptom Checklist, Derogatis, 1994), ao Inventário Clínico de Auto Conceito (Serra, 1986) e à Escala de Depressão de Auto Avaliação de Zung (Zung, 1965). O processo de intervençáo passou pelo acompanhamento individual de forma a desenvolver o sentido de realidade e solidez interna de Maria. Neste sentido e tendo em conta a problemática da paciente, considerou-se pertinente iniciar um processo terapêutico face à 
ilusão idealizante que mantinha com o objeto perdido. Deste modo, a abordagem face ao estado de depressividade passará por um agravamento da mesma, pois somente assim Maria será capaz de amar um objeto novo (Matos, 2001).

Dado que Maria vivencia um luto a intervenção passará também pela aceitação e elaboraçáo da perda. Sobretudo pelo que Matos (2001) designou de vivência e aceitação do sentimento de perda. Nesse sentido a intervenção visa a desconstruir a relaçáo que Maria tenta manter com esse objeto ausente do real, que é idealizado, e desvinculá-la do mesmo com vista ao crescimento e individuação.

Assim sendo, tratou-se de uma perspectiva de ajuda, sem que nenhuma estratégia específica fosse concebida, ou seja, criou-se a oportunidade de que Maria suscitasse os conflitos, com a certeza de que nada lhe seria imposto ou objetado. Com o objetivo final de ajudar o seu desenvolvimento pessoal, com vista a permitir que viva com a sua realidade, pensar e elaborar sobre as dificuldades que the causam angústia e sofrimento interno.

\section{Avaliação psicológica}

No seguimento do processo de avaliaçáo, verificou-se uma ênfase em alguns aspectos em particular, como seja, a agitação interna e humor depressivo. Para além disso, ficou patente certa oscilação de humor, registrando-se ainda a queixa de que, em momentos de ansiedade, desenvolve tremores acompanhados de perda total da visão. Para além disso, Maria manifesta irritabilidade e marcada ansiedade. Apesar de Maria ter conseguido manter o contato ocular, a primeira sessão foi marcada por inquietação motora. Ficou ainda patente um baixo sentido de significações em relação à sua problemática.

Após a recolha da história clínica, Maria foi esclarecida acerca da importância de elaborar um conhecimento mais consistente de si, pelo que foi proposta uma avaliaçáo psicológica. Salienta-se que Maria se manteve cooperante durante todo o processo, embora denotando ansiedade. Deste modo, no seguimento da avaliação psicológica, tornou-se pertinente recorrer a meios auxiliares de diagnóstico no sentido de obter uma descrição e compreensão, a mais profunda e completa possível, da personalidade da Maria. Este processo incluiu vários momentos e resultou da complementação de diversos instrumentos. Neste sentido, recorreu-se ao teste de personalidade de Rorschach (Sistema Compreensivo de Nina Rausch, Rorschach, 1953), ao SCL-90 (Symptom Checklist, Derogatis, 1994), ao Inventário Clínico de Auto Conceito (Serra, 1986), e à Escala de Depressão de Auto-Avaliação de Zung (Zung, 1965). Numa primeira fase e de forma a obter um quadro geral sobre a sintomatologia da Maria recorreu-se à escala de sinto- 
matologia SCL-90. Assim sendo, Maria apresentou valores assinaláveis nos itens referentes a: somatização, depressão, ansiedade, fobia e alteraçóes de sono. $\mathrm{O}$ alto valor nos itens depressão e ansiedade está de acordo com alguns aspectos referentes à vivência pessoal de Maria. A somatização está presente pelas queixas corporais frequentes que Maria revela, nomeadamente a perda de visão em momentos de descontrole e as faltas de ar. Relativamente, o alto valor nos itens de fobia está em conformidade com os medos constantes expressos por si. Apesar de ser uma escala de autopreenchimento, os valores são congruentes com o relato da Maria.

Relativamente ao Inventário Clínico de Auto Conceito a paciente demonstra um autoconceito geral abaixo da média. Revela uma visão de autoeficácia pouco abaixo da média, visão de maturidade e visão de impulsividade pouco acima da média, e ainda uma visão de aceitação social acima da média. Estes dados encontram-se coerentes com sua história, dado que a Maria manifesta falta de confiança e é extremamente autodesvalorizante, mostrando-se insegura em relação a qualquer atitude que tenha de tomar (Derogatis, 1994).

Quanto à Escala de Auto-avaliação de Depressão de Zung, Maria obteve um resultado de 49 pontos, indicando a presença de um quadro depressivo grave. Este resultado é congruente com tudo o que nos foi possível observar em relação à paciente durante todo o processo de avaliação psicológica (Zung, 1965).

Por último, o teste de personalidade de Rorschach foi aplicado na terceira sessão, uma vez que, pelo seu cariz de abordagem, o estabelecimento de uma relação de confiança e percepção de aceitação facilitou o processo. Maria aceitou a tarefa de imediato, mostrando-se cooperante durante a avaliação psicológica realizada e percebendo, sem dificuldade, as indicaçóes para a execução do teste proposto.

Relativamente aos resultados do teste de personalidade de Rorschach, a paciente adotou uma atitude de oposição face ao mesmo, bem como uma postura defensiva contra a angústia suscitada pelos conteúdos subjacentes a esta prova clínica. $\mathrm{O}$ peso do real e do concreto paralisou e inibiu o movimento associativo, evitando o confronto com os movimentos pulsionais reativados e sentidos como perturbadores ou perigosos, optando, então, por um controle da realidade externa, percebida objetivamente, e pela manifestação reduzida da realidade interna. Sugere tratar-se de uma pessoa com vivência do tipo introversivo misto, isto é, mais orientada para o interior, menor capacidade de adaptação ao real e contato mais intensivo do que extensivo. Apresenta capacidade apreensiva de forma globalizada, com pouca tendência para a particularidade. É uma pessoa pouco perceptiva, ou seja, não se preocupa com detalhes. Para além disso, não utiliza o pensamento categorial como 
estratégia de abordagem do estímulo, tem desinteresse pela realidade e pelo concreto. Deste modo, manifesta tendência para apreensóes em forma inteira e de projeçáo de forma una e coesa, evidenciado capacidade de apreender o objeto como total e diferenciado, pressupondo a existência de um self com integridade assegurada. Ao apreender o objeto no seu todo, em detrimento do esforço para a construção e elaboração criativa das manchas, evita uma procura profunda e íntima de si, bem como a emergência de afetos e representaçôes internas. Os resultados indicam uma personalidade algo imatura, frágil, apoiada em mecanismos de defesa de natureza neurótica (banalização, evitamento, regressão). Neste sentido e apesar de uma capacidade intelectual média, a utente recorre frequentemente ao pensamento banal, infantil e estereotipado, de forma a sentir-se mais incluída e protegida pelo meio social e afetivo. Aproxima-se da realidade pelo global, pela defensiva, com falha de inteligência prática e pragmática. No que diz respeito à resolução de conflitos perante os estímulos, revela ineficácia na utilização de mecanismos de defesa, o que pode gerar angústia. Embora Maria tente e pretenda estar integrada e conformada socialmente, os seus recursos cognitivos são mal utilizados para o efeito, e os esforços de intelectualização são ineficazes. O julgamento que usa para interpretar o exterior náo é adequado, o que pode remeter para o fato de que os afetos e emoçóes perturbam essa operaçáo intelectual e, por isso, o seu ego não é forte o suficiente para garantir a regulação e o controle em função das experiências e percepçóes. Deste modo, a Maria mantém-se ligada ao mundo exterior, mas de forma perturbada. Para além disso, parece apresentar dificuldades no nível da representação do casal parental, assim como problemas sexuais na dimensão fálica (Rorschach, 1953).

\section{Resultados - diagnóstico psicológico}

Depois de ter sido realizada a avaliação compreensiva da problemática de Maria, pode perceber-se uma dinâmica emocional e relacional marcada por sentimentos de angústia. A paciente mostrou-se pouco funcionante e com um registo pouco consciente face à sua problemática e pouca capacidade de significação em relação à mesma. Deste modo, a avaliação parece revelar uma vivência afetiva de tipo neurótico. A Maria apresenta sinais clínicos evidentes da angústia da perda do objeto e da separaçáo afetiva, revelando fortes sentimentos de culpabilidade frente a conflitos internos. Sobressai uma personalidade depressiva com traços de irritabilidade, humor depressivo onde surgem episódios depressivos que envol- 
vem tristeza, inferioridade e culpa. De acordo com Matos (2001), não é possível existir uma depressão sem sentimentos de culpa, inferioridade e baixa autoestima, uma vez que a "perda do amor do objeto" causa principal da depressão é significativamente desnarcisante. Parece que a Maria se debate numa luta interna, onde se desenvolvem sentimentos de ansiedade, tristeza e irritabilidade gerando tensões que colmatam na somatização, através da perda de visão. Para além disso, registra-se numa vivência de luto não resolvido ou fantasiado agravante deste quadro. Pode-se concluir a presença de uma pessoa com capacidade intelectual média baixa, cuja efetivação na realidade se encontra comprometida por quadro de natureza depressivo - de características neuróticas.

\section{Discussáo - análise compreensiva da problemática}

O enquadramento das vivências de Maria remete para uma perturbação neurótica marcada por uma depressão com sintomas desproporcionados, consecutiva de experiências penosas reconhecidas. Não apresenta ideias delirantes nem alucinaçóes, contudo as suas preocupaçóes são centradas no traumatismo psíquico que agravou a doença, nomeadamente a morte do pai.

A depressão neurótica é marcada pela ideia prevalecente e constante sobre a qual não se estabelece a luta (Matos, 2001). O mesmo se verifica no caso da Maria, ou seja, um agravamento significativo em situaçóes de perda, não que esteja habituada ao sofrimento, mas de alguma forma parece tornar-se dependente do mesmo.

Maria debate-se contra a angústia da perda do objeto e da separação afetiva. Investindo assim numa relação de objeto do tipo analítico, ou seja, uma relação a dois em que existe uma idealização do objeto externo, neste caso o seu pai (Bergeret, 1998). Verificando-se uma procura de uma relação de dependência e suporte, o que justifica a dependência emocional que Maria apresenta em relação ao pai e à mãe. Segundo, Matos (2001, p. 41) "na condição depressiva o indivíduo ama por dependência afetiva, porque precisa do amor do outro". Verifica-se uma necessidade constante de ser amado e admirado pelos outros, uma vez que o depressivo é na sua essência verdadeiramente pobre em sentimentos de autoestima e autovalorização.

Para além disso, Maria debate-se com problemas de desvinculação das figuras parentais. De acordo com Matos (2001) o neurótico debate-se com o medo de separação. Verifica-se no caso de Maria o que o autor designa de "angústia de separação", ou seja, a paciente apresenta um medo constante em se 
afastar do objeto de segurança narcísica e objeto funcional. Winnicott (citado por Matos, 2001) definiu este estado pela "ausência de capacidade de estar só", consequente de uma ligação excessivamente fusional com o objeto, anteriormente com o pai agora transferido para a mãe. Segundo Matos (2001) esta situação pode também perpetuar-se pelo escasso desenvolvimento das habilidades pessoais. Este aspecto é definido pelo autor como a instabilidade neurótica, fazendo parte da vivência de Maria. Esta idealização do pai e dependência do objeto resulta no que Matos (2001) designou no desejo de se elevar ao estatuto de supremo juiz do sujeito, alimentando assim a libido exibicionista. Neste sentido Maria atua não por prazer próprio, mas para agradar ao objeto e ser por este admirada. Deste modo, o exagerado investimento neste objeto primitivo e nos objetivos infantis de amor-carinho e necessidade de proteção impedem a paciente de investir e transferir a libido para novos objetos e objetivos. No que Matos (2001) descreveu de novos objetivos genitais e de independência, de objetos diferentes, nomeadamente, exogâmicos.

A vivência de luto colocou estes aspectos vivenciais da Maria mais presentes, sendo que a depressão parece complicar a resolução do luto, ou seja, este processo de luto parece ter reavivado o medo de perda e insegurança na relação, o que leva a paciente a procurar uma segurança na figura da mãe.

Segundo Rocha (2008) as crises de depressão neurótica estão relacionadas a vivências traumatizantes causadas por frustraçóes afetivas, nomeadamente pelo medo do abandono e pelas experiências dolorosas da perda e da falta que Maria tem vivenciado também pela morte do pai. Estas vivências fomentam a frustração, a atitude agressiva, o sentimento de culpa e o medo de perder o amor dos outros, sobretudo dos pais, presentemente da mãe (Bin, 1998). Para além disso, verifica-se que Maria concentra a libido no desejo infinito por um encontro irrecuperável, ou seja, vive ilusoriamente à espera do regresso do pai. Assim sendo, o trabalho de recuperar o objeto perdido e a integridade narcísica ocupa todo o espaço, tempo e energia, o que oblitera o prazer de viver, a possibilidade de amar e de se relacionar com outros objetos (Daniel \& Souza, 2006). Por conseguinte, verifica-se que os filhos e o marido da Maria são de alguma forma colocados de lado em prol das necessidades pessoais que tem para consigo mesma. Negligencia o papel de mãe, fato de que nem sempre tem consciência, todavia quando percebe alguns indícios de tal situaçáo sente-se culpabilizada e revoltada consigo mesma. Deste modo, parece que Maria se debate com uma vivência depressiva, responsável por perturbar o seu estado mental, deixando-a emocionalmente instável, o que a conduz para um adoecer psicológico. 


\section{Intervençáo - acompanhamento psicológico}

O processo de acompanhamento psicológico decorreu com uma periodicidade semanal e duração média em torno de 55 minutos por sessão. A abordagem inicial foi orientada com vista a recolher a história de vida de Maria e a enquadrá-la na sua vivência atual. Para além disso, a par de uma atitude terapêutica desenvolvida desde logo, iniciou-se o processo de avaliação psicológica com vista a um conhecimento mais profundo da vivência e problemática da paciente. A avaliação psicológica sucedeu com o consentimento de Maria e no momento em que se começava a estabelecer uma relação de confiança e percepção de aceitação.

Posteriormente, Maria foi sendo acompanhada criando espaço para a elaboraçáo do seu sofrimento, dado que as sessôes decorreram com as dificuldades que trazia para as mesmas. Desta forma, e sem traçar determinantes específicos, tentou-se facilitar a mudança terapêutica através da criação das condições que desenvolvessem o sentido de realidade e aceitação pessoal aumentando a solidez interna da paciente.

Neste sentido, na sessão quatro Maria manifestou-se angustiada e triste pela morte do pai a quem estava fortemente ligada. Neste ponto, ficou patente uma tristeza que é sentida, mas em que a realidade da perda é negada na sua vivência atual. Desta forma, entendeu-se que o processo terapêutico da Maria passaria pela realizaçáo de um trabalho de luto que estava bloqueado. Numa tentativa de se perceber como foi vivenciada a morte do pai, a Maria descreve que foi um "choque" e que na altura vivenciou tudo de forma "anestesiada, e nem da cerimónia se lembra!” (sic). Uma vez tomado conhecimento da perda, o choque emocional constitui, geralmente, a primeira reação ao luto (Rebelo, 2009). Nos dias subsequentes à morte verificou-se uma negação do sucedido. A negação de um sentimento de perda impede que o trabalho de luto se realize, pois a tristeza mantém-se e a depressão arrasta-se (Matos, 2001). Neste sentido, tentou-se que a Maria elaborasse acerca do que significou perder o pai. De forma a identificar e resolver os conflitos causados pela perda e ausência, todavia neste momento Maria apresenta-se apenas capaz de descrever revolta.

Relativamente às sessóes cinco e seis a paciente apresentou estados de humor semelhantes, nomeadamente, irritabilidade e anedonia. Inicialmente, não associa a nenhum evento específico. Neste sentido e de forma a melhor compreender a situaçáo deu-se espaço para que a Maria explicasse melhor o que tem vivido e como se tem sentido. Foram devolvidas as atribuiçôes que a paciente faz em relação a estes aspectos, acabando por afirmar que provavelmente se deve à proximidade do dia do pai, desenvolvendo pensamentos cada vez mais recorrentes em torno deste. 
Maria acrescenta ainda que provavelmente não viveu a morte do pai como devia ter sido, pois não se permitiu sofrer nem demonstrar emoção (sic). Atualmente, reconhece que está a viver o que não viveu anteriormente.

$\mathrm{Na}$ sessão sete ficou patente uma maior estabilidade emocional por parte de Maria. Revela um episódio específico, que ainda não tinha sido capaz de fazer desde a morte do pai, nomeadamente a sua ida ao cemitério no dia do pai. Questionada sobre a forma como se sentiu nesta situação afirma que "sentiu saudades, acompanhadas de alguma tristeza por não ter o pai presente, mas, sobretudo, sentiu-se aliviada" (sic). Sublinha que o ter conseguido entrar no cemitério foi uma conquista. Para além disso, acrescenta que se sentiu calma e tranquila naquele momento, ao contrário do que antes acontecia. Foi devolvido à paciente que o poder recordar a morte do pai sem tanto sofrimento passaria por aceitar o que aconteceu. Deste modo, Maria acrescenta que conseguiu tolerar a angústia e náo teve a vontade que tinha de "querer arrancar o pai dali" (sic). Para além disso, refere que ao entrar sozinha no cemitério conseguiu estar mais consigo própria e com os seus pensamentos. Julgamos que este passo constituiu um aspecto fundamental para Maria que está mais capaz de se encontrar com os seus sentimentos e tolerar os sofrimentos que estes acarretam.

Nas sessóes oito e nove ficou patente certa labilidade de humor, pelo que a vivência de Maria oscila entre a calma vs. tranquilidade, irritação vs. impulsividade (sic). De acordo com Rebelo (2009), à medida que os caminhos de busca do objeto perdido fracassam, a impaciência aumenta, e a irritação generalizada e agressividade passam a ser os eixos do comportamento com as pessoas próximas. Questionada acerca desta oscilação, Maria não associa a nenhum evento específico (sic). Destaca o cariz incomportável da situação uma vez que a impulsividade e irritabilidade fácil lhe provocam consequências na relação com as pessoas próximas. Evidencia uma situação específica com o marido, nomeadamente um desentendimento conjugal que Maria associa à forma impulsiva e descontrolada como lidou com o mesmo. Para além disso, acrescenta que a impaciência se alastra aos filhos. Descreve ainda que faz uma fuga de tudo o que lhe possa recordar o pai, nomeadamente idas à igreja.

Neste sentido, foi reformulado o pedido inicial da paciente em relação ao acompanhamento psicológico, acabando por manifestar o desejo que tem em se tornar mais independente (sic). Acrescenta ainda que se começa a sentir demasiado dependente da mãe, e isso lhe provoca consequências negativas a si e à mãe. Numa tentativa de compreensão da problemática percebeu-se que Maria quer mudar esta situação pelos sentimentos de insuportabilidade e repercussóes que lhe causa, em relação à mãe verifica-se um esforço para autonomizar a filha. Maria 
sugere que tudo está relacionado com a morte do pai e com o medo que tem em perder a mãe. De acordo com Matos (2001, p. 45) e sob a perspectiva de Freud, o luto (depressão normal) e a melancolia (depressão patológica) reúnem aspectos em comum, apesar de distintos. Deste modo, o luto refere-se a uma reação normal e necessária em relação à perda de um objeto importante, e a melancolia diz respeito a uma "reação patológica de uma personalidade marcada pela extrema dependência objetal”. Note-se que este medo excessivo não abrange outras pessoas, nomeadamente, o marido, o que reforça a canalização deste medo de perda para as figuras primárias de cuidado.

Na sessáo doze Maria sublinha em si a presença constante do pai pelo que existem hábitos e rituais que perpetua pela ilusão do regresso deste. A obsessão na pessoa perdida é um elemento constante da busca, em que a exigência de presença é efetiva podendo-se revelar por diversas vias. Assim sendo, a demonstração da fixação de proximidade pode ser realizada através de rituais e comportamentos ligados à pessoa perdida (Rebelo, 2009).

As sessóes seguintes têm como referência um sentimento de angústia e ansiedade, possivelmente pelo reconhecimento da perda e consequente desorganização emocional. De acordo com Rebelo (2009) a desorganização das emoçóes constitui um processo que decorre com a reconhecida irreversibilidade da privação do ente querido. Percebemos uma Maria confusa e reticente que apesar de tudo mantém uma luta interna, todavia parece ficar suspensa pelo medo que a mudança acarreta.

Após a sessão quinze Maria parece sugerir uma ligeira mudança, salientando que se sente mais relaxada, embora ainda angustiada, pelo que tem pensado mais acerca de si (sic). Os sentimentos face à figura paterna constituem ainda uma parte significativa do seu mal-estar, todavia Maria afirma agora sentir saudades e tristeza (sic), ao invés do sentimento de revolta de outrora. Possivelmente, a tristeza advém do reconhecimento irreversível da perda, constituindo um indício importante de que a paciente começa a ultrapassar uma das fases iniciais do luto, que implica a passagem da revolta para uma fase de saudade, em que vai progressivamente aceitando o sucedido. Salientou-se a pertinência de Maria se permitir viver esta fase, estando consciente que a saudade e possível aceitação não significam esquecer ou desrespeitar a memória do pai, tratando-se apenas de uma fase necessária para uma vivência mais saudável. Devolveu-se à paciente que a morte do pai parece não ser a única questão que constitui a problemática vivencial, todavia ao permitir aceitar e resolver cada um desses aspectos poderá conseguir viver melhor e com menos sofrimento. Percebe-se uma fragilidade emocional significativa ao que acresce uma vivência enquadrada na depressão neurótica, relacionada 
à vivência de frustraçóes afetivas, pelo que apesar do findar do processo Maria teria ganhos importantes em continuar em acompanhamentos psicológico.

\section{Conclusáo - resultado do processo terapêutico}

$\mathrm{Na}$ fase inicial do processo do processo de acompanhamento, Maria revelou grandes dificuldades em descrever os seus pensamentos e sentimentos, manifestando uma falta de atribuição de sentido face à sua problemática. A dificuldade da paciente em verbalizar os seus conflitos e angústias conduzia-a frequentemente à somatização. Deste modo, considera-se que a Maria, gradualmente, foi alargando a sua perspectiva sobre si e alterando o seu modo de funcionamento interno, demonstrando que estava mais atenta às suas queixas, ao seu corpo, aos seus pensamentos e sentimentos. $\mathrm{Na}$ fase terminal do acompanhamento de Maria, verificou-se uma diminuição da ansiedade como atenuação dos pensamentos ruminativos em torno da morte do pai e dependência da mãe. Apesar de gradualmente se evidenciar a tentativa de desenvolver uma maior independência, continua a verificar-se um estabelecimento de uma relação simbiótica com a mãe. Para além disso, também se verificou uma maior capacidade para pensar sobre os seus sentimentos e emoçôes, facilitando o processo de elaboração dos seus conflitos internos.

\section{Referências}

Bergeret, J. (1998). Psicologia patológica: teoria e clínica. Lisboa: Climepsi Editores.

Bin, K. (1998). Fenomenologia da depressão estado-limite. Revista Latinoamericana de Psicopatologia Fundamental, 1(3), 11-32.

Daniel, C., \& Souza, M. (2006). Modos de subjetivar e de configurar o sofrimento: depressão e modernidade. Psicologia em revista, 12(20), 117-130.

Derogatis, L. R. (1994). SCL-90-R: Symptom cheklist - 90- R. Administration, scoring and procedures manual. Minneapolis: National Computer Systems.

Kübler-Ross, E. (1969). On death and dying. New York: Macmillan.

Matos, A. C. (2001). A depressão. Lisboa: Climepsi Editores.

Rebelo, J. E. (2009). Amor, luto e solidão. Alfragide: Casa das Letras.

Rocha, Z. (2008). Para uma abordagem estrutural da depressão: contribuiçóes freudianas. Psyche, 12(23), 0-0.

Rorschach, H. (1953). Psychodiagnostic. Paris: Presses Universitaires de France.

Psic. Clin., Rio De JANeiro, vol. 25, N.I I, P. I 97 - 21 3, 2013 
Serra, A. V. (1986). O inventário clínico de auto-conceito. Psiquiatria Clínica, 7(2), 67-84.

Zung, W. W. (1965). A self-rating depression scale. Archives of General Psychiatry, 12(1), 63-70.

\section{Nota}

${ }^{1}$ Este trabalho é financiado por Fundos FEDER através do Programa Operacional Factores de Competitividade - COMPETE e por Fundos Nacionais através da FCT - Fundação para a Ciência e a Tecnologia no âmbito do projecto FCOMP-01-0124-FEDER-022714.

Recebido em 16 de dezembro de 2011 Aceito para publicação em 29 de abril de 2012 